\title{
Integrated prospecting prediction of multi-scale structure information at Gaosong field in Gejiu, Yunnan Province
}

\author{
Chun Zhong $\mathrm{Ni}^{1, \mathrm{a}}$ and Hua Fan ${ }^{1, \mathrm{~b}}$ \\ ${ }^{1}$ Faculty of Land Resources Engineering, Kunming University of Science and Technology, \\ Kunming, China 650093

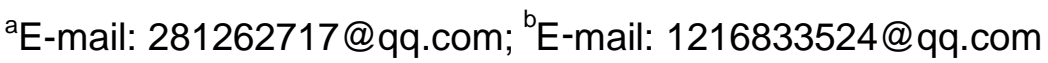

Keywords: Multi- scale; Synthetic information; Multifractal analysis; Metallogeny; Gejiu.

\begin{abstract}
Gejiu tin ore zone is one of the largest tin polymetallic ore zone and takes the most important roles in the southeast Yunnan province. Gaosong field is located in north east of Gejiu mining district Fault structure of Gaosong field in the Gejiu tin deposits plays an important role in controlling ore emplacement. Research on the fractal characteristics of fracture for prospecting the region has very high reference value The classic definition of fractal space is covered within the desired dimension of the feature size segment, a disc, or the number of spheres. The box counting method is alwayls beniful and calculated with the fracture network coverage and the number of boxes needed to box size.By analyzing $300 \mathrm{~km}^{2}$ remote sensing images of Gejiu tin deposit and Gaosong ore field, the box counting method is used to statisticalize the fracture fractal characteristics, and the results showing Gaosong ore field exploration prospect well.
\end{abstract}

\section{Geological background of regional metallogeny and Gaosong field geology}

At present multi-scale research focused on trace elements fractal statistics with the application of the mining method, study the singularity features of local enrichment of mineralization elements[1-3]。 Using the generalized self-similarity principle method of nonlinear theory to carry out the old regional exploration geochemistry data processing and delineat ore anomalies.Zeng-hua Li study the size of the magnetic pyrite particles, irregularity and space distribution characteristics based on GIS fractal model (circumference - area)。Gao yin concludes element distribution has the characteristics of scale invariance by analysising Gejiu tin stream sediment elements $(\mathrm{Sn}, \mathrm{Cu}$ and $\mathrm{Pb})$ multifractal in large scale and small scale range respectively[4-7].

Gaosong field is one of the major producing mines of Yunnan Tin company, which is located in north east of gejiu mining district. There is no ore outcrops in the earth's surface. Tin-polymetallic deposits only are found in lutangba, Machishui, GaoFengshan. Mineral deposits generally stripe along the NE Lutangba fault.

Faults can be divided into four groups, that is EW, NE, NW andSN. EW-trending faults from North to South have Gesong fracture, Qilinshan fracture, Machishui fracture, Gaoa fault, Beiyinshan fault. These faults are nearly equidistant distribution. NE-trending faults includes Lotus mountain, Lutangba fracture, Linaxi fracture from west and east. NW-trending faults major contain DaJingdong,Heimashi, Tuofengshan, Axizhai and LinA fracture. SN group fracture does not develop. 


\section{Box counting method}

Currently, we always usethe box counting method to calculate it, which is calculated with the fracture network coverage and the number of boxes needed to box size[8-10], generally expressed as follows:

$$
N(r) \sim r^{-D}
$$

D is fractal dimension, $N(r)$ is an estimate of the length of the fractal object, area or volume.In practice, the overall pattern of the fracture is defined to the cover object which the size is $r$ for the number of $N(r)$ changes with the following formula

$$
\begin{aligned}
& N(r) \approx r^{-D} \\
& p_{i}(r)=\frac{L_{i}(r)}{\sum_{1}^{n} L_{i}(r)}
\end{aligned}
$$

Therefore, through making $\mathrm{r}$ and $N(r)$ double logarithmic plot, the fractal dimension $\mathrm{D}$ can be obtained from the slope of the line. This method has been widely used to measure the fractal dimension of the fracture network.

\section{Analysis of fault structures in the Eastern gejiu mining area}

Available information shows that above $90 \%$ ore deposits distribute in eastern region of gejiu Tin polymetallic. During the deposits formation, fault structure plays an important role in controlling ore-body emplacement. Therefore, researching on the fracture fractal characteristics of has very high reference value for prospecting and exploration.

Figure 1 shows 1:100000 TM image as linear structural interpretation in the study area. As a result, the fractal theory is applied to the method of dimension. For the whole Gejiu east mineralization zone, known Ma Lage ore fields, Malage and Laochang field, Kafang field and the predicted gaosong ore field fractal analysis are conducted within the fracture tectonic system. Gejiu mineralization covers an area of $300 \mathrm{~km} 2$ (about $15 \mathrm{~km}$ from east to west, $20 \mathrm{~km}$ north to south).In a grid of 5-0.5 km length scale the fracture structure enters the logarithm of total number of grid and the grid side of logarithmic, which has good linear correlation. The correlation coefficient $r=0.999$, the fractal dimension $\mathrm{D}=1$. 8491.In the rest of the four subsystems area, the grid for $1-0.1 \mathrm{~km}$ in length scale the fracture structure enters the logarithm of total number of grid and the logarithm of grid side also has a good linear correlation: Ma Lage field $r=0.9902, \mathrm{D}=1.5134$; Laochang and mines fields $r=0.9891, \mathrm{D}=1.5786$; Kafang $\mathrm{r}=0.9902 \mathrm{D}=1.4480$, Gaosong $\mathrm{r}=0.9905, \mathrm{D}=1.5319$. The results Illustrate two-dimensional plane fracture structure system in 5-0.5 km long scale follows fractal distribution in the eastern Gejiu area. The other four ore fields' two-dimensional plane fracture structure also obeys fractal distribution.within 1-0.1 km scale 


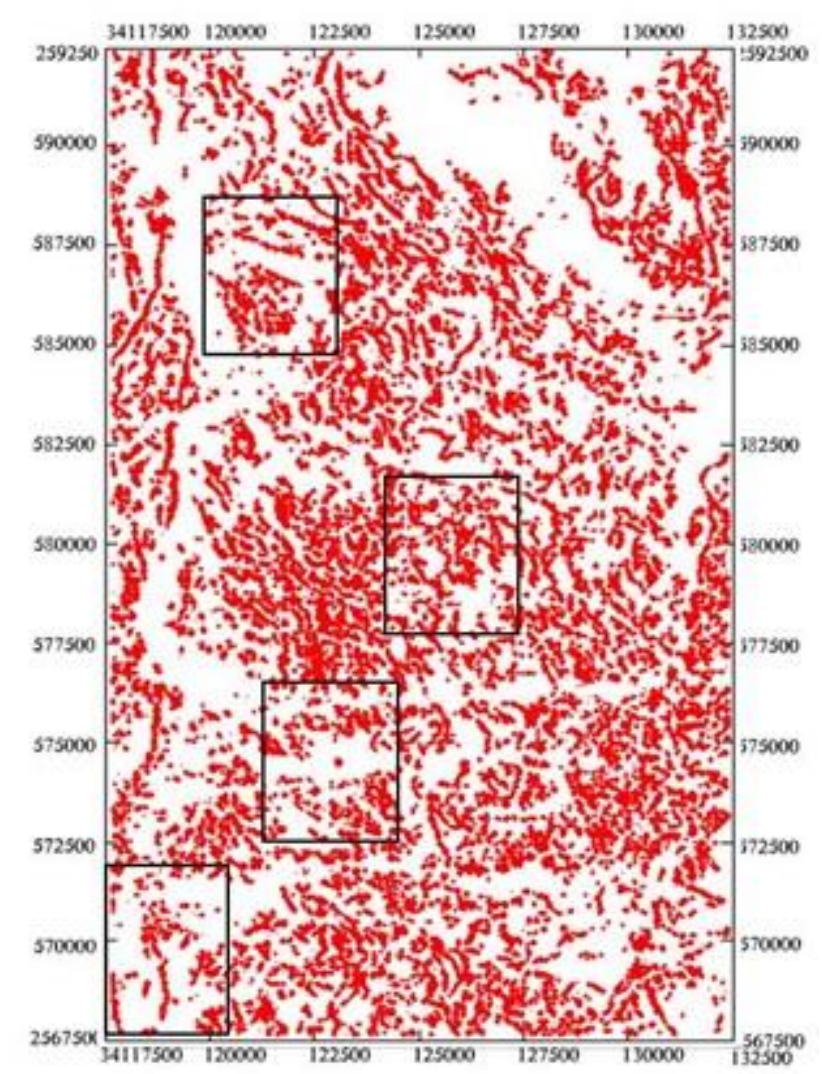

Figure.1 Remote-sensing interpretation map of

Gejiu mining district

From the fractal diagram of fault structure in Gejiu eastern mine area (Figure 2 ), we can clearly see in four ore field, Laochang ore fields' analysising dimensions D Value (1.5786) is maximum. This is corresponding with the geologic fact its resources in four ore field is the largest, accounting for about half of the entire eastern gejiu mining area resources. If Faults fractal dimension value in a two-dimensional plane is bigger, the reserves of the ore field will be greater. At this point, the gaosong field reserves are smaller than the Laochang ore fields, but bigger than Malage and Kafang ore field. Therefore, Gaosong ore field has great potential for exploration. The fractal dimension $\mathrm{D}(1.8491)$ are greater than the four sub-regions in the whole eastern Gejiu. It may account for there are large ore field in eastern Gejiu area, which have not been revealed so far and the exploration potential is still very high.
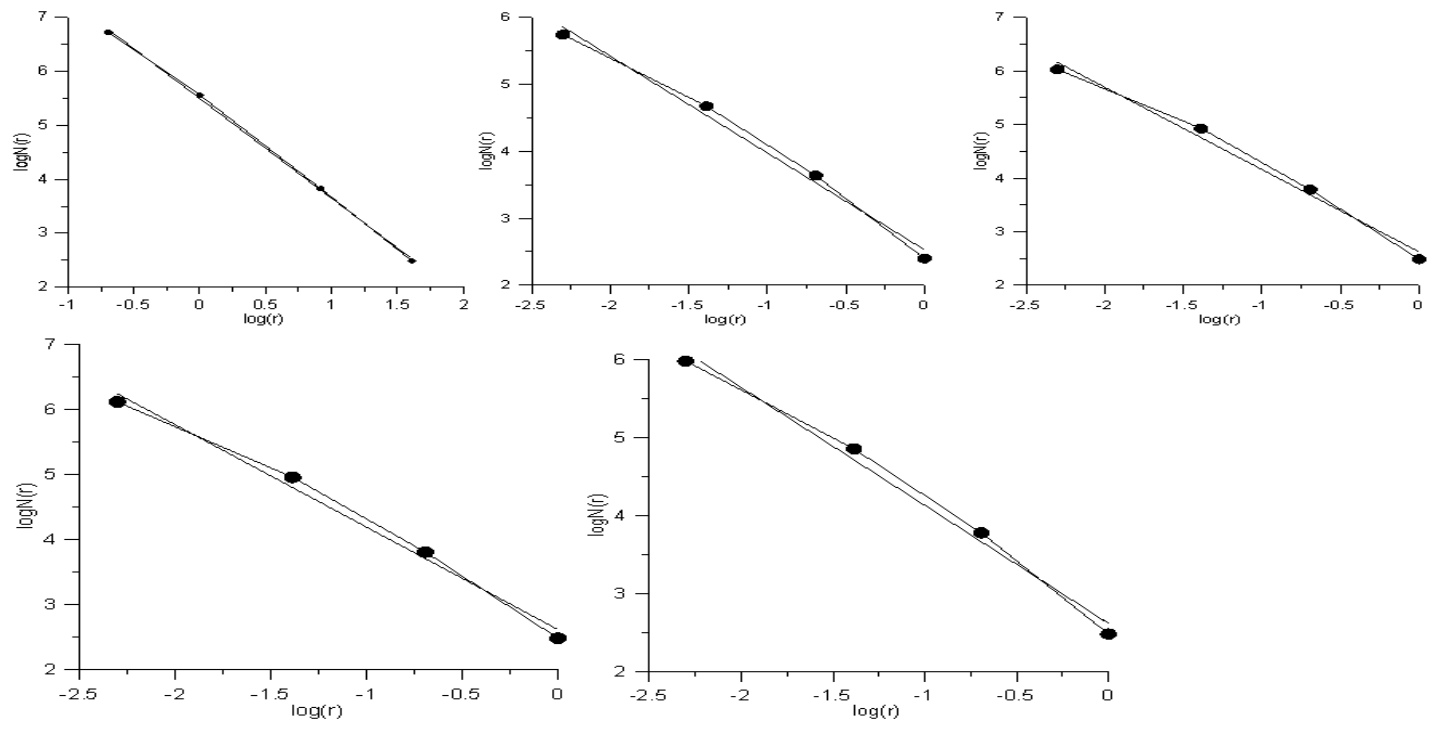

Figure. 2 Faults fractal of east Gejiu mining district 


\section{Conclusion}

By analyzing $300 \mathrm{~km}^{2}$ remote sensing images of Gejiu tin deposit and Gaosong ore field, the box counting method is used to statisticalize the fracture fractal characteristics, and the results showing Gaosong ore field exploration prospect well.

Ma Lage field $D=1.5134$; Laochang $D=1.5786$; Kafang $D=1.4480$, Gaosong $D=1.5319$. The results Illustrate the four ore field obeying fractal distribution within 1-0.1 km scale

The eastern Gejiu tin ore area fractal dimension $\mathrm{D}(1.8491)$ is greater than the other four sub-regions. It may account for the large ore field in Gejiu Eastern area still exist and the exploration potential is still very high.

\section{References}

[1] F.S. Dai, Characteristics and Evolution of Rock Series, Lithogenesis, Metallogenesis of Crust-Derived Anatectin Magma in Gejiu Ore Field. Geology of Yunnan, Vol.15(1996) No,4,P.330-344

[2] De Dreuzy J.R.,Darcel C.,Davy P.,etal, Influence of Spatial Correlation of Fracture Centers on the Permeability of Two-Dimensional Fracture Networks Following a Power Law Lengthdistribution.Water Resour. Res, Vol.22(2004) No,1,P 40

[3]P.A.Dowd, J.A.Martin, A Three-Dimensional Fracture Network Data Set For a Block of Granite. International Journal of Rock Mechanics \& Mining Sciences, Vol.46(2009) No,4,P. 811-818

[4] D Marsan, Can coseismic stress variability suppress seismicity shadows? Insights from a rate-and-state friction model.Geophys. Res, Vol.111(2006) No,1,P. 312

[5] W.L.Power, W.B.Durham, Topography of natural and artificial fractures in granitic rocks:Implications for studies of rock friction and fluid migration.Rock Mech Min Sci \& Geomech, Vol.34(1997), P. 979-989

[6] V.V.Mourzenko, J.F.Thovert, P.M.Adler, Macroscopic permeability of three-dimensional networks with power-law size distribution.Phys. Rev, Vol.5(2004) No,69,P. 307

[7] A.Nur, The origin of tensile fracture lineaments.Struct. Geol, Vol.4(1982),P. 31-40

[8] N.E. Odling, Network Properties of a Two-dimensional Natural Fracture Pattern. Pageoph, Vol.138(1992), No,1,P. 95-114

[8] N.E. Odling, Scaling and connectivity of joint system in sandstones from western Norway.Struct. Geol, Vol.19(1997), P. 1257-1271

[9] D.C.P.Peacock, D.J.Sanderson, Displacements, segment linkage and relay ramps in normal fault zones.Struct. Geol, Vol.13(1991), P. 721-733

[10] C.I.Mc Dermott, O.Kolditz , Geomechanical model for fracture deformation under hydraulic, mechanical and thermal loads.Hydrogeol, Vol.14(2006) No,4,P. 485-498 